\title{
A crítica literária em periódicos brasileiros contemporâneos: uma aproximação inicial
}

Regina Dalcastagnè ${ }^{1}$

\section{Sobre reconhecimento, legitimação e metodologia}

Se entendemos a literatura como um campo, no sentido que a sociologia de Pierre Bourdieu (1996) dá à palavra - um espaço estruturado e hierarquizado de disputas entre agentes que interiorizam um conjunto de práticas e de interesses -, então é preciso reconhecer que o que está em jogo nesse campo é a possibilidade de consagração, que assume a forma do reconhecimento pelos pares. Escritores ou editores podem ser sensíveis a incentivos de mercado ou a outras vantagens materiais, mas, enquanto integrantes do campo literário, o que os move é a busca desse reconhecimento, que não é necessariamente o do grande público de leitores comuns. É o reconhecimento oferecido pelos demais integrantes do campo literário.

Aqui, o que se pode chamar de "crítica universitária" (a interpelação da literatura feita a partir do universo acadêmico) ganha relevância. Professores e pesquisadores de literatura participam do campo literário em posição singular, que não corresponde às posições de escritores, editores ou mesmo jornalistas culturais. Envolvidos também em disputas por reconhecimento entre si, nós somos agentes importantes na legitimação de autores/as e obras, o que fazemos ao incluí-los no corpus de nossas disciplinas, ao orientar dissertações e teses e também ao dedicar a eles nosso esforço de pesquisa, que resulta em trabalhos apresentados em eventos acadêmicos, em livros e, especialmente, em artigos publicados em periódicos científicos.

A publicação em periódicos é, hoje e já há bastante tempo, o principal instrumento de divulgação do conhecimento, em todas as áreas do saber. Apesar dos desafios apresentados pelas novas plataformas tecnológicas, em particular a internet, que exigem uma adequação de suas práticas, as revistas acadêmicas continuam sendo o canal por excelência de escoamento da produção intelectual das universidades. Os próprios

\footnotetext{
${ }^{1}$ Doutora em teoria literária e professora da Universidade de Brasília (UnB), Brasília, DF, Brasil. Dorcid.org/0000-0003-2251-8022. E-mail: rdal@unb.br
} 
periódicos, por sua vez, encontram-se hierarquizados, por meio de rankings formais ou informais, que são objeto de disputas e atribuem importância e prestígio diferenciados a cada um deles.

O peso da crítica universitária é visível na definição e redefinição do cânone passado, mas é ainda mais crucial no que diz respeito à produção literária contemporânea. Para obras que ainda não possuem um lastro de crítica e camadas de interpretações acumuladas, a atenção oferecida pelos acadêmicos representa um capital importante. O escritor Antônio Torres, em uma palestra na Universidade de Brasília há alguns anos, dizia que poderíamos falar mal ou nem lembrar de Paulo Coelho nas universidades, porque isso não abalaria suas vendas. No entanto, se não falássemos dele, Antônio Torres, ele simplesmente deixaria de existir. Justamente por isso, analisar os artigos produzidos sobre literatura contemporânea nos periódicos acadêmicos é uma via promissora para entender aspectos da configuração atual do campo literário brasileiro.

O mapeamento da crítica literária acadêmica no Brasil (que tem os mesmos moldes de pesquisa realizada anteriormente sobre o romance brasileiro contemporâneo) ${ }^{2}$ buscou identificar quais as correntes mais presentes, os autores de referência e as obras citadas em alguns dos periódicos mais representativos da área nos últimos 15 anos. Entendendo que os estudiosos de literatura no Brasil (e, é claro, alguns pesquisadores que atuam em instituições do exterior) não formam um corpo monolítico, mas possuem uma razoável pluralidade interna, a abordagem propunha não apenas uma comparação diacrônica, mas também a inclusão de elementos que possibilitassem comparações sincrônicas, segundo critérios de geração, região, instituição de origem e gênero, entre outros. ${ }^{3}$

Para isso, foram selecionadas, inicialmente, dez periódicos com certa tradição e bem classificados no ranking mais importante do mundo acadêmico brasileiro, o Qualis da Coordenação de Aperfeiçoamento de Pessoal de Nível Superior (Capes), segundo a atualização ocorrida no início de 2012 e válida até 2015. Devido ao imenso número de revistas de Letras, optou-se por trabalhar apenas

\footnotetext{
${ }^{2}$ Para mais detalhes, ver Dalcastagnè $(2005 ; 2010 ; 2011)$.

3 A pesquisa foi contemplada com financiamento do Conselho Nacional de Desenvolvimento Científico e Tecnológico (CNPq), e teve coordenação conjunta com os professores Anderson Luís Nunes da Mata e Igor Ximenes Graciano.
} 
com aquelas que obtiveram nota máxima - A1 -, tendo em vista que a nota reflete a abrangência, a circulação, a periodicidade, em suma, a relevância da revista na área. Além disso, o recorte buscou as publicações cujo interesse fosse, de fato, a literatura (ainda que algumas alternassem seus números entre literatura e linguística). E, uma vez que havia a preocupação de se entender como a literatura brasileira vem sendo trabalhada no meio acadêmico, evitou-se revistas com foco exclusivo em literaturas estrangeiras.

A ideia inicial era abarcar periódicos de todas as regiões do país. E aí começaram os problemas: Norte e Nordeste não possuíam, e continuam não possuindo, nenhuma revista classificada como A1 no Qualis Capes. Sendo assim, optou-se por incluir as duas revistas das associações da área - a Associação Brasileira de Literatura Comparada (ABRALIC) e a Associação Nacional de Pós-Graduação e Pesquisa em Letras e Linguística (ANPOLL) - em seu lugar, compreendendo que elas reúnem, necessariamente, produções de diferentes Estados brasileiros. Surgiu, então, o problema do Sudeste, região com algumas das mais importantes universidades do país e com elevado número de periódicos com nota A1. Decidiu-se incluir duas revistas de cada um dos três principais Estados da região: Minas Gerais, Rio de Janeiro e São Paulo. Para evitar a repetição das mesmas instituições, foram escolhidas uma revista da capital e outra do interior de cada Estado. Também houve a preocupação em selecionar periódicos que já estivessem, é claro, em atuação desde antes de 2000.

Foram selecionadas, portanto, as revistas listadas a seguir.

Do Sudeste:

- Minas Gerais: O Eixo e a Roda (UFMG) e Ipotesi (UFJF)

- Rio de Janeiro: Gragoatá (UFF) e Terceira Margem (UFRJ)

- São Paulo: Literatura e Sociedade (USP) e Itinerários (UNESPAraraquara)

Do Sul:

- Rio Grande do Sul: Letras de Hoje (PUC-RS)

Do Centro-Oeste:

- Distrito Federal: Estudos de Literatura Brasileira Contemporânea (UnB)

Das Associações:

- Revista da ANPOLL e Revista Brasileira de Literatura Comparada 
Os cálculos iniciais apontavam um volume de cerca de 220 edições de revistas. Estimava-se que a base de dados final conteria cerca de 3.000 artigos. A responsabilidade pela leitura e fichamento desse material, sob supervisão direta dos coordenadores da pesquisa, foi de um grupo de estudantes dos cursos de graduação em Letras e em Direito da Universidade de Brasília. A pesquisa contou ainda com apoio de duas estudantes de pós-graduação. ${ }^{4}$

Cada artigo foi lido e fichado separadamente por dois estudantes da equipe; em caso de discordância, havia revisão em reuniões coletivas. A fim de garantir a homogeneidade na aplicação dos critérios de preenchimento, reduzindo os casos de discrepância, as fichas buscavam dados objetivos. Além disso, houve um cuidadoso treinamento inicial da equipe, com discussões sobre a crítica literária brasileira e reuniões quinzenais, ou mesmo semanais, em que todas as fichas preenchidas no período foram discutidas com os demais integrantes da equipe e com os pesquisadores responsáveis pela supervisão. Por fim, criamos um manual de preenchimento, com as dúvidas mais comuns. Tratava-se de um método que, como disse antes, já havia sido testado, com sucesso, no mapeamento de autores/as e personagens de quase 700 romances brasileiros contemporâneos.

A ficha incluía, além da identificação do artigo, dados sobre os autores (instituição, sexo, geração, área disciplinar), sobre a temática (em especial se tratava de literatura brasileira), sobre a abrangência (se monográfica, comparativa ou panorâmica) e sobre os autores/as estudados. Também indicava o tipo de enfoque (exclusivo no objeto, mais histórico ou mais sociológico, vinculado à tradição literária) e, quando fosse o caso, a relação com outras artes e mídias. Foram coletados todos os resumos e palavras-chave, além dos nomes dos autores/as teóricos/as e críticos/as citados na bibliografia.

A tabulação foi feita no software estatístico Sphinx Lexica, que, além de funcionar como banco de dados, permite o cruzamento de inúmeras

\footnotetext{
${ }^{4}$ Deixo aqui registrado os agradecimentos, pelo empenho e seriedade na condução das leituras e fichamentos ao longo da pesquisa, a Amanda Maria Garcia Holgado de Oliveira, Ana Cristina Viana Barboza de Oliveira, Carina Rodrigues Lobato, Daniel Pinho Rocha, Edson Junio Dias de Sousa, Gustavo Alexandre de Paiva, Isadora Maria Santos Dias, João Pedro Coleta da Silva, Juliana Sampaio Mota, Laís Oliveira Alves, Marcos Eduardo Lopes Rocha, Maria Manuella Bessa Kury, Raysa Ferreira Soares, Waldson Gomes de Souza, Vanessa Chanice Magalhães Silva. Paula Q. Dutra e Graziele Frederico auxiliaram na organização dos dados e na preparação do material para divulgação.
} 
variáveis. Como resultado do levantamento, foram identificadas as linhas de força da discussão acadêmica sobre literatura no Brasil, sua evolução nos últimos 15 anos, as diferenças de acordo com as gerações de pesquisadores e os focos de interesse das diferentes instituições. Os dados levantados nessa pesquisa permitem um debate mais consistente sobre a crítica literária acadêmica produzida hoje no Brasil e sobre os próprios periódicos mais bem conceituados.

\section{Resultados}

Ao longo de quase dois anos, foram lidos e fichados os textos publicados em nove revistas: O Eixo e a Roda (UFMG), Gragoatá (UFF), Itinerários (UNESP-Araraquara), Letras de Hoje (PUC-RS) e Estudos de Literatura Brasileira Contemporânea (UnB), Literatura e Sociedade (USP), Ipotesi (UFJF) e a Revista Brasileira de Literatura Comparada e a Revista da Anpoll. Ao final, decidiu-se deixar de fora a revista Terceira Margem (UFRJ), tendo em vista que sua publicação foi interrompida em 2012. No total, foram trabalhados 3.085 textos; no entanto, 520 deles, embora publicados nas revistas dedicadas à literatura, estavam fora do escopo da pesquisa. Na maior parte dos casos, são artigos sobre linguística, que aparecem misturados em algumas edições. Aqueles números que incluíam exclusivamente textos sobre linguística, como acontece na Letras de Hoje, por exemplo, não foram sequer incluídos no corpus básico; no entanto, foram encontrados vários artigos de linguística "infiltrados" entre os de literatura. Também foi frequente a presença de textos de sociologia, antropologia, história em meio a dossiês que ofereciam uma discussão mais interdisciplinar sobre o tema proposto.

Foram analisados, então, 2.565 textos que têm como foco a literatura, mesmo que tragam apenas uma abordagem teórica. O número de textos que trabalham, de fato, com obras literárias é de 2.155. Portanto, os dados apresentados aqui, dependendo da seleção, podem trazer essas diferenças. Há inúmeros cruzamentos possíveis e importantes a serem feitos; optei, neste artigo, por trazer apenas os dados mais relevantes para uma primeira aproximação. A Tabela 1 apresenta o número total de artigos analisados. 
Tabela 1 - Número total de textos analisados por revista (2000-2014)

\begin{tabular}{l|c|c}
\hline \multicolumn{1}{c|}{ Revistas } & Total & Sobre literatura \\
\hline Estudos de Literatura Brasileira Contemporânea & 410 & 396 \\
Letras de Hoje & 406 & 321 \\
Revista da ANPOLL & 375 & 214 \\
Ipotesi & 374 & 348 \\
Itinerários & 374 & 328 \\
Gragoatá & 341 & 251 \\
O Eixo e a Roda & 276 & 265 \\
Literatura e Sociedade & 273 & 206 \\
Revista Brasileira de Literatura Comparada & 256 & 236 \\
\hline Total & $\mathbf{3 . 0 8 5}$ & $\mathbf{2 . 5 6 5}$ \\
\hline
\end{tabular}

Fonte: Pesquisa "A crítica literária em periódicos brasileiros contemporâneos".

Ao contrário do que foi demonstrado na pesquisa sobre autoria no romance brasileiro contemporâneo (que apontava menos de $30 \%$ de escritoras em cerca de 700 obras publicadas), ${ }^{5}$ a maioria dos textos acadêmicos foi escrita por mulheres $(57,7 \%$ do total, $58,1 \%$ dos que tratam de literatura). ${ }^{6}$ Apesar de as mulheres serem maioria entre os autores publicados, isso não se reflete no número de escritoras analisadas nos textos e tampouco no número de críticas ou teóricas citadas nas referências bibliográficas dos artigos - em ambos os casos, há uma gritante maioria de homens, como se verá mais adiante. ${ }^{7}$

Com a intenção de saber quais literaturas são estudadas nas universidades brasileiras, também se estabeleceu a pergunta sobre a origem das obras e autores estudados, para melhor situá-las em relação ao escopo (Tabela 2). Assim, foram deixadas de fora revistas bem conceituadas sobre literaturas estrangeiras. Ainda que as revistas estudadas publiquem também pesquisadores internacionais, eles são poucos e contribuem para o mesmo processo de legitimação de autores e obras no Brasil. Constatou-se, então, que quase metade dos artigos tratam

${ }^{5}$ Para uma discussão sobre a participação das mulheres no campo literário, como autoras e personagens do romance brasileiro contemporâneo, ver Dalcastagnè (2010).

${ }^{6}$ Nos textos em coautoria, considerou-se o sexo do primeiro autor.

${ }^{7}$ Não deixa de ser significativo observar que, mesmo as mulheres tendo o maior número de publicações nas revistas A1 - que contam como indicador central de produção intelectual qualificada nos rankings acadêmicos brasileiros -, dos 175 nomes da área contemplados com bolsas de produtividade do CNPq hoje, 87 são mulheres e 88 são homens. 
exclusivamente sobre literatura brasileira. Ao somar os estudos comparativos que incluem literatura brasileira, tem-se cerca de 59\%.

Tabela 2 - Origem das obras analisadas nos artigos

\begin{tabular}{l|c|c}
\hline \multicolumn{1}{c|}{ Origem } & № & Porcentagem \\
\hline Só literatura brasileira & 1.269 & $49,5 \%$ \\
Literatura brasileira e outra(s) & 234 & $9,1 \%$ \\
Só outra(s) & 652 & $25,4 \%$ \\
Teoria literária & 410 & $16,0 \%$ \\
\hline Total & $\mathbf{2 . 5 6 5}$ & $\mathbf{1 0 0 \%}$ \\
\hline
\end{tabular}

Fonte: Pesquisa "A crítica literária em periódicos brasileiros contemporâneos".

Obs.: Incluídos apenas os artigos que tratam de literatura.

Os valores são bastante similares quando se observa o recorte temporal dos autores estudados (Tabela 3). Na pesquisa, entendemos como contemporâneos os autores/as que tiveram produção significativa após os anos 1970. Para esta análise, os textos que tratam exclusivamente de teoria literária foram retirados do universo total. Mais de $50 \%$ dos artigos se debruçam apenas sobre a literatura contemporânea. Incluídas também as que tratam, simultaneamente, de obras contemporâneas e de outras épocas, são pouco mais de $63 \%$. Ao contrário do que se imaginava inicialmente, o peso da Estudos de Literatura Brasileira Contemporânea, com seu recorte temporal explícito, na produção deste índice não é tão elevado. Com a revista colocada à parte, os percentuais ficam, respectivamente, em $44,9 \%$ e $57,0 \%$. São dados que se contrapõem à reclamação frequente de que a universidade vira as costas à produção literária contemporânea.

Tabela 3 - Época das obras analisadas nos artigos

\begin{tabular}{l|c|c}
\multicolumn{1}{c|}{ Época } & № & Porcentagem \\
\hline Só contemporânea & 1.107 & $51,4 \%$ \\
Contemporânea e outra(s) & 253 & $11,7 \%$ \\
Só outra(s) & 795 & $36,9 \%$ \\
\hline Total & $\mathbf{2 . 1 5 5}$ & $\mathbf{1 0 0 \%}$ \\
\hline
\end{tabular}

Fonte: Pesquisa "A crítica literária em periódicos brasileiros contemporâneos".

Obs.: Incluídos apenas os artigos que tratam de obras literárias. 
O dado seguinte, que envolve a abrangência dos artigos publicados (Tabela 4), é revelador do modo como estudamos e organizamos o conhecimento sobre literatura nas universidades. São quase dois terços de trabalhos monográficos, ou seja, focados em uma única obra ou em um único autor. Curioso é que mesmo na Revista Brasileira de Literatura Comparada, os artigos monográficos são ampla maioria (57,5\%). De forma ampla, entendemos como comparativos os textos que abordam pelo menos duas obras ou dois autores diferentes aproximando-os entre si, e como panorâmicos aqueles que discutem um conjunto maior de obras e autores, muitas vezes sem se deter em uma comparação mais detalhada entre eles. Em 55 artigos, mais de 10 autores foram trabalhados de maneira simultânea.

Tabela 4 - Abrangência dos textos

\begin{tabular}{l|c|c}
\hline \multicolumn{1}{c|}{ Abrangência } & № & Porcentagem \\
\hline Monográfica & 1.427 & $66,2 \%$ \\
Comparativa & 388 & $18,0 \%$ \\
Panorâmica & 340 & $15,8 \%$ \\
\hline Total & $\mathbf{2 . 1 5 5}$ & $\mathbf{1 0 0 \%}$ \\
\hline
\end{tabular}

Fonte: Pesquisa "A crítica literária em periódicos brasileiros contemporâneos".

Obs.: Incluídos apenas os artigos que tratam de obras literárias.

Em relação aos dados sobre os gêneros e temas mais trabalhados (Tabela 5), o romance, como já se esperava, toma a dianteira. No campo literário e mesmo no mercado editorial brasileiro das últimas décadas, o romance é considerado o gênero literário por excelência, quase que exigindo dos autores/as sua adesão para que possam ser, efetivamente, chamados de escritores/as. Por outro lado, a literatura infantojuvenil continua sendo o patinho feio dos estudos literários. Embora seja a produção que atinge um público mais amplo - especialmente a partir das compras governamentais para as bibliotecas das escolas públicas -, ela costuma ser desprezada como objeto de investigação na área de Letras, ficando comumente relegada aos estudiosos da Pedagogia. É provável que exista uma barreira, gerada pelo preconceito, nas próprias revistas, entre editores e pareceristas, o que desestimularia os pesquisadores a produzirem sobre o tema, em um círculo vicioso que impede o desenvolvimento dos estudos sobre a literatura infantojuvenil na área. A opção por manter a categoria isolada (em vez de tê-la 
dispersado entre romance, poesia e conto) está relacionada com a intenção de dar visibilidade a essa discussão.

É interessante também observar a forte presença de outras mídias (com 14,2\%) entre os estudos sobre literatura. O cinema contribui com uma boa parcela desse número, mas há ainda artigos sobre as redes sociais e as novas plataformas digitais. Já a discussão sobre o campo literário (com 7,7\%) envolve, por exemplo, análises sobre feiras de livros, recepção de traduções no exterior, movimentos de escritores, manifestos etc. Essas duas categorias foram introduzidas após o préteste do questionário, uma vez que abrangiam uma quantidade significativa de textos e não se enquadravam na divisão dos gêneros.

Tabela 5 - Gênero das obras e temáticas estudadas nos artigos

\begin{tabular}{l|c|c}
\hline \multicolumn{1}{c|}{ Gênero/Temática } & № & Porcentagem \\
\hline Romance & 1.007 & $46,7 \%$ \\
Poesia & 513 & $23,8 \%$ \\
Conto & 363 & $16,8 \%$ \\
Crítica & 334 & $15,5 \%$ \\
Outras mídias & 305 & $14,2 \%$ \\
Campo literário & 167 & $7,7 \%$ \\
Memórias & 139 & $6,5 \%$ \\
Não ficção & 118 & $5,5 \%$ \\
Teatro & 116 & $5,4 \%$ \\
Crônica & 70 & $3,2 \%$ \\
Infantojuvenil & 40 & $1,9 \%$ \\
\hline Total & $\mathbf{2 . 1 5 5}$ & \\
\hline
\end{tabular}

Fonte: Pesquisa "A crítica literária em periódicos brasileiros contemporâneos".

Obs.: Eram possíveis respostas múltiplas nesta variável. Foram incluídos apenas os artigos que tratam de obras literárias.

Por fim, a pesquisa também indagou o que chamamos de "enfoque" dos artigos (e aqui voltam todos os textos que tratam de literatura, incluindo os exclusivamente teóricos), isto é, as ferramentas mobilizadas para compreender seu objeto (Tabela 6). É pertinente observar o contraponto entre os trabalhos, majoritários, com uma visada que abrange o mundo ao redor, através do aporte da sociologia, história e antropologia; e o recorte exclusivo no objeto, ou seja, que não dialoga com nada fora do corpus, sequer com a própria tradição literária. Apesar 
do número elevado de artigos com essa perspectiva restrita, percebe-se que, somando-se as demais abordagens - filosofia/psicanálise, a própria tradição literária e a relação com outras mídias - esse enfoque é minoritário nos estudos literários atuais.

Tabela 6 - Enfoque dos artigos

\begin{tabular}{l|c|c}
\hline \multicolumn{1}{c|}{ Enfoque } & № & Porcentagem \\
\hline Sociologia/antropologia/história & 1.432 & $55,8 \%$ \\
Exclusivo no objeto & 796 & $31,0 \%$ \\
Filosofia/psicanálise & 510 & $19,9 \%$ \\
Tradição literária & 500 & $19,8 \%$ \\
Outras mídias & 178 & $6,9 \%$ \\
\hline Total & $\mathbf{2 . 5 6 5}$ & \\
\hline
\end{tabular}

Fonte: Pesquisa "A crítica literária em periódicos brasileiros contemporâneos".

Obs.: Eram possíveis respostas múltiplas nesta variável. Incluídos apenas os artigos que tratam de literatura.

Outros dados reveladores dizem respeito aos/às escritores/as mais estudados nas revistas. Pressupõe-se que se um pesquisador produz um artigo sobre determinado/a autor/a é porque já trabalha de alguma forma com sua obra, especialmente em sala de aula - o que implica na legitimação e na contínua propagação de seu nome. A primeira questão a se ressaltar nesse conjunto de dados é a subrepresentação feminina. Embora outros nomes surjam aqui e ali, apenas Clarice Lispector, Carolina Maria de Jesus e Conceição Evaristo se destacam dentro desse perfil. Entre elas, o volume de trabalhos sobre Lispector é significativamente maior, 47 no total, enquanto Jesus tem 9 e Evaristo tem apenas 7. Outro dado relevante é o fato de que quase todos os autores, e as raras autoras, com maior presença no corpus dos artigos são brasileiros. As exceções são de escritores portugueses e hispano-americanos já consagrados do século XX: José Saramago e Jorge Luis Borges, mais especificamente.

A pesquisa aponta diferenças importantes de acordo com a abrangência do artigo, se monográfico, comparativo ou panorâmico. Somando-se a frequência dos/as autores/as em todas as categorias, temos os nomes preferidos dos estudos literários brasileiros: Guimarães Rosa (com 121 textos), Machado de Assis (com 108), Carlos Drummond de Andrade (com 51), Antonio Candido (também com 51), Clarice 
Lispector (com 47) e Mário de Andrade (com 39). O curioso aqui é a presença de Antonio Candido entre os nomes de romancistas e poetas. Nesta lista, ele não aparece como referencial crítico, mas como objeto de análise - o que demonstra sua importância e sua renovada influência dentro do campo acadêmico da literatura no Brasil. De resto, os nomes não são uma surpresa para quem estuda a literatura brasileira. Mas vale notar as alterações de acordo com a abrangência do artigo. Alguns autores parecem ser entendidos como "grandes demais" para dividir a análise com outros, enquanto nomes da literatura marginal, como Ferréz e Paulo Lins, além da própria Carolina Maria de Jesus, costumam ser discutidos em grupo, em textos panorâmicos. Embora a lista dos/as escritores/as analisados apenas pelas autoras mulheres não seja muito diferente, é interessante notar que Clarice Lispector passa de quinto para terceiro lugar entre os textos monográficos; e Carolina Maria de Jesus aparece na décima posição.

Em textos monográficos os autores/as mais estudados são, nesta ordem: Guimarães Rosa (com 82 textos); Machado de Assis (65); Antonio Candido (41); Carlos Drummond de Andrade (27); Clarice Lispector (26); José Saramago (23); Mário de Andrade (18); Oswald de Andrade (12); Chico Buarque (11); Graciliano Ramos (11); Milton Hatoum (11); José de Alencar (10); e Lúcio Cardoso (10).

Nos textos em que a abrangência era comparativa, os autores mais trabalhados são bastante semelhantes: Guimarães Rosa (com 31 textos); Machado de Assis (19); Carlos Drummond de Andrade (11); José de Alencar (11); Euclides da Cunha (10); Mário de Andrade (10); Jorge Luis Borges (9); João Gilberto Noll (8); Antonio Candido (7); Clarice Lispector (7); Conceição Evaristo (7); Fernando Pessoa (7); Graciliano Ramos (7); e José Saramago (7).

Já nos textos panorâmicos, o corpus muda um pouco, apesar da liderança de Machado de Assis (com 24 textos); seguido de Ferréz (17); Oswald de Andrade (17); Paulo Lins (16); Clarice Lispector (14); Carlos Drummond de Andrade (13); Sérgio Sant'Anna (13); Augusto de Campos (11); José de Alencar (11); Mário de Andrade (11); Bernardo Carvalho (10); Haroldo de Campos (9); Jorge Luis Borges (10); Carolina Maria de Jesus (9); e João Gilberto Noll (9). Campeão nas outras categorias, Guimarães Rosa aparece aqui apenas oito vezes. Nesse conjunto de textos, quando havia mais de 10 autores trabalhados eles foram considerados "múltiplos" e seus nomes não estão computados. Entendeu-se que, nesses 
casos, dificilmente haveria uma análise mais aprofundada de cada um deles e que sua inclusão poderia distorcer o mapeamento.

Os dados sobre os críticos e teóricos mais citados nas bibliografias dos artigos, mesmo naqueles que só trabalham com teoria, também são bastante reveladores da configuração de nosso campo acadêmico. Antonio Candido, em primeiro lugar, comparece em 393 artigos, seguido por Walter Benjamin (em 256); Roland Barthes (214); Michel Foucault (170); Mikhail Bakhtin (162); Jacques Derrida (159); Roberto Schwarz (151); Gilles Deleuze (145); Silviano Santiago (143); Alfredo Bosi (137); Haroldo de Campos (119); Stuart Hall (108); Luiz Costa Lima (105); e Pierre Bourdieu (101). Ressalte-se que a primeira mulher a aparecer nesta lista, a norte-americana Linda Hutcheon, citada em 94 artigos, não trabalha com questões de gênero.

De um modo geral, tendo em vista os dados levantados, não há muita diferença entre a produção das autoras e dos autores. Os homens tendem a escrever mais artigos com enfoque exclusivamente teórico (18,4\% dos artigos deles, $14,8 \%$ dos artigos delas). As mulheres trabalham um pouco mais com a literatura contemporânea (Tabela 7) e tendem a realizar mais trabalhos monográficos e menos panorâmicos (Tabela 8), mas os números também são bastante semelhantes.

Tabela 7 - Período das obras analisadas, por sexo do autor do artigo

\begin{tabular}{c|c|c|c|c}
\hline $\begin{array}{c}\text { Sexo do } \\
\text { autor }\end{array}$ & $\begin{array}{c}\text { Só contemporânea } \\
\text { (\%) }\end{array}$ & $\begin{array}{c}\text { Contemporânea } \\
\text { e outras (\%) }\end{array}$ & Só outras (\%) & Total \\
\hline Feminino & $53,1 \%$ & $11,2 \%$ & $35,7 \%$ & $\mathrm{n}=1278$ \\
Masculino & $48,8 \%$ & $12,5 \%$ & $28,7 \%$ & $\mathrm{n}=877$ \\
\hline
\end{tabular}

Fonte: Pesquisa “A crítica literária em periódicos brasileiros contemporâneos".

Obs.: Incluídos apenas os artigos que tratam de obras literárias.

Tabela 8 - Abrangência dos artigos, por sexo do autor

\begin{tabular}{c|c|c|c|c}
\hline $\begin{array}{c}\text { Sexo do } \\
\text { autor }\end{array}$ & Monográfica (\%) & Comparativa (\%) & Panorâmica (\%) & Total \\
\hline Feminino & $66,6 \%$ & $18,0 \%$ & $15,4 \%$ & $\mathrm{n}=1278$ \\
Masculino & $65,7 \%$ & $18,0 \%$ & $16,3 \%$ & $\mathrm{n}=877$ \\
\hline
\end{tabular}

Fonte: Pesquisa "A crítica literária em periódicos brasileiros contemporâneos".

Obs.: Incluídos apenas os artigos que tratam de literatura.

Há algumas diferenças mais significativas em relação ao gênero e à temática analisados. As mulheres trabalham mais com o conto do que os 
homens e também são mais propícias a analisar a literatura infantojuvenil. Por outro lado, os homens investigam mais a poesia e a própria crítica literária do que as mulheres.

Tabela 9 - Gênero analisado e temática dos artigos, por sexo do autor

\begin{tabular}{l|c|c}
\hline & \multicolumn{2}{|c}{ Sexo do autor } \\
\hline \multicolumn{1}{c|}{ Gênero literário } & $\begin{array}{c}\text { Feminino } \\
(\mathbf{n = 1 . 2 7 8 )}\end{array}$ & $\begin{array}{c}\text { Masculino } \\
\text { (n = 877) }\end{array}$ \\
\hline Romance & $47,6 \%$ & $45,5 \%$ \\
Poesia & $22,2 \%$ & $26,1 \%$ \\
Conto & $18,8 \%$ & $14,0 \%$ \\
Crítica & $13,1 \%$ & $19,0 \%$ \\
Outras mídias & $13,4 \%$ & $15,3 \%$ \\
Campo literário & $7,3 \%$ & $8,4 \%$ \\
Memórias & $7,4 \%$ & $5,1 \%$ \\
Não ficção & $5,4 \%$ & $5,6 \%$ \\
Teatro & $5,7 \%$ & $4,9 \%$ \\
Crônica & $3,4 \%$ & $3,1 \%$ \\
Infantojuvenil & $2,6 \%$ & $0,8 \%$ \\
\hline
\end{tabular}

Fonte: Pesquisa "A crítica literária em periódicos brasileiros contemporâneos".

Obs.: Eram possíveis respostas múltiplas. Incluídos apenas os artigos que tratam de literatura.

Muitos outros cruzamentos podem ser feitos, além de análises mais detalhadas dos números apresentados. É possível observar, por exemplo, as diferenças estabelecidas por gênero, faixa etária e instituição dos/as autores/as. Também podemos pensar diferenças entre as revistas e regiões onde estão abrigadas. Mas já temos aí algumas pistas importantes para repensarmos nossa própria produção. Sobre quem estamos falando afinal? Quem escolhemos legitimar? O referencial teórico que utilizamos é congruente com o que queremos discutir? Quanto estamos nos repetindo e repetindo o que já disseram antes de nós? O que falta estudar? O que permanece como território interditado nos estudos literários?

Para dar conta, de fato, do que está sendo pensado e produzido dentro das universidades brasileiras, seria preciso complementar esse levantamento com vários outros, por exemplo, sobre as teses e dissertações recém-defendidas ou ainda em andamento. Com o acelerado crescimento dos programas de pós-graduação na área e a 
inclusão de jovens pesquisadores de outros estratos sociais, podemos ter um novo perfil de pesquisa se desenhando, sem que esteja já revelado nas revistas acadêmicas analisadas - uma vez que elas publicam quase que exclusivamente doutores. Também o catálogo de livros acadêmicos da área deveria ser observado. No Brasil, embora a avaliação de cursos e currículos supervalorize a publicação de artigos em revistas mais bem conceituadas, é comum que estudantes e pesquisadores busquem suas referências principais nos livros, entendidos como espaço de consolidação de ideias. Programas de disciplinas, bibliografias para entrada em cursos de pós-graduação, corpus de textos apresentados nos principais encontros da área - é todo um universo que movimenta a discussão sobre o literário e que ainda precisa ser investigado. Afinal, é mais do que hora de repensarmos nossos procedimentos e nossa intervenção na construção do conhecimento sobre a literatura no país.

\section{Referências}

BOURDIEU, Pierre (1992/1996). As regras da arte: gênese e estrutura do campo literário. Tradução de Maria Lucia Machado. São Paulo: Companhia das Letras.

DALCASTAGNÈ, Regina (2005). A personagem do romance brasileiro contemporâneo (1990-2004). Estudos de Literatura Brasileira Contemporânea, Brasília, n. 26, p. 13-71.

DALCASTAGNÈ, Regina (2010). Representações restritas: a mulher no romance brasileiro contemporâneo. In: DALCASTAGNÈ, Regina; LEAL, Virgínia Maria Vasconcelos (Org.). Deslocamentos de gênero na narrativa brasileira contemporânea. Vinhedo: Horizonte.

DALCASTAGNÈ, Regina (2011). A personagem negra na literatura brasileira contemporânea. In: DUARTE, Eduardo de Assis; FONSECA, Maria Nazareth (Org.). Literatura e afro descendência no Brasil: antologia crítica. Belo Horizonte: Editora da UFMG. v. 4 ("História, teoria, polêmica"). p. 309-37.

DALCASTAGNÈ, Regina (2012). Literatura brasileira contemporânea: um território contestado. Rio de Janeiro: Editora da UERJ; Vinhedo: Horizonte.

Recebido em 20 de novembro de 2017.

Aprovado em 16 de março de 2018. 


\section{resumo/abstract/resumen}

\section{A crítica literária em periódicos brasileiros contemporâneos: uma aproximação inicial}

Regina Dalcastagnè

A partir do mapeamento e análise da crítica literária acadêmica produzida no Brasil nos últimos 15 anos, busca-se observar como a literatura brasileira (e, mais especificamente, a literatura brasileira contemporânea) é abordada nessas revistas. Com a leitura e fichamento de mais de 3 mil artigos, procurou-se identificar quais as correntes mais presentes, os autores de referência, as obras mais citadas. A intenção é alcançar um conhecimento mais profundo tanto sobre a crítica no meio universitário quanto sobre os mecanismos de legitimação do campo literário brasileiro.

Palavras-chave: crítica, periódicos, literatura brasileira contemporânea.

\section{Literary criticism in contemporary Brazilian periodicals: an initial approximation}

Regina Dalcastagnè

By mapping the scholarly production from the last fifteen years, this article seeks to understand how Brazilian literature, and, in particular contemporary Brazilian literature, is broached in this output. The essay examines a corpus of more than three thousand articles to identify some of the most common literary trends, which authors are frequently referenced, and which works are quoted the most. The essay aims to better understand academic scholarship and to pinpoint the mechanisms of legitimization in the field of Brazilian literature.

Keywords: criticism, periodicals, contemporary Brazilian literature.

\section{La crítica literaria en periódicos brasileños contemporáneos: una aproximación inicial}

Regina Dalcastagnè

A partir del mapeo y análisis de la crítica literaria académica producida en Brasil en los últimos quince años, se busca observar cómo la literatura brasileña (y más concretamente la literatura brasileña contemporánea) es abordada en estas revistas. Con la lectura y fichamiento de más de 3.000 artículos, se buscó identificar cuáles son las corrientes más presentes, los autores de referencia y las obras más citadas. La intención es alcanzar un conocimiento más profundo sobre la crítica en el medio universitario y sobre los mecanismos de legitimación del campo literario brasileño.

Palabras clave: crítica, periódicos, literatura brasileña contemporânea. 